\title{
Are current archiving systems reliable enough?
}

\author{
Parham Habibzadeh $^{1}$
}

Received: 29 May 2015 / Accepted: 13 July 2015 / Published online: 30 July 2015

(C) The International Urogynecological Association 2015

\section{Dear Editor,}

I read with interest the editorial recently published in International Urogynecology Journal on reference rot [1]. In fact, what has been mentioned in the article is consistent with the findings of many other studies [2-4]. A study conducted in 2013 showed that about half of the articles published in the British Medical Journal and The Lancet cited at least one URL and that these URLs had a half-life of 4.7 years [2]. In addition, recent efforts to preserve URLs reflect a growing global concern about losing parts of the evidence published in scientific literature as time goes by. As mentioned in the editorial, this obstacle might partially be resolved by using various archiving systems. Besides Perma, there are many other preserving systems. WebCite is another one [5]. However, such preserving systems may encounter onand-off service interruption so that the preserved URLs are not available now and then. Furthermore, there is no guarantee that they will be working forever. Lack of a trustworthy archiving system for such a huge amount of data in the medical literature increases the complexity of the current situation, and that is probably why, for the time being, many of the leading medical journals have

Parham Habibzadeh

parham.habibzadeh@yahoo.com

1 Student Research Committee, Shiraz University of Medical Sciences, Shiraz, Iran decided to ignore this long-lasting issue and have refused to trust in these archiving systems. Another solution for this problem for journals published by mainstream publishers such as Springer, Elsevier, etc., would be to archive all the URLs cited in their journals on a single server - sponsored by these mighty publishers - to guarantee the permanent survival of these references.

Despite the multitude of research conducted to evaluate the references to URLs cited in general medical journals, further inquiries into the pattern and the trend of citation of these references in subspecialty journals is highly needed. These studies will unravel the magnitude of data lost in various areas of medicine each day due to this problem and will hopefully pave the way for a unanimous decision by the publishers to archive these URLs on a tried and tested archiving system.

Conflicts of interest None

\section{References}

1. Riss P (2015) Reference rot: does it matter? Int Urogynecol J 1-2. doi: 10.1007/s00192-015-2707-8.

2. Habibzadeh P (2013) Decay of references to web sites in articles published in general medical journals: mainstream vs small journals. App Clin Inform 4:455-464

3. Rochon PA, Wu W, Gurwitz JH, Kalkar SR, Thomson J, Gill SS (2015) Prospective evaluation of the accessibility of internet references in leading general medical journals. Scientometrics 102:13751384

4. Thorp AW, Schriger DL (2011) Citations to web pages in scientific articles: the permanence of archived references. Ann Emerg Med 57: $165-168$

5. http://www.webcitation.org/. Accessed 29 May 2015 